\title{
The Development of Next-generation PBMC Humanized Mice for Preclinical Investigation of Cancer Immunotherapeutic Agents
}

\author{
Y. MAURICE MORILLON II, ARIANA SABZEVARI, JEFFREY SCHLOM* and JOHN W. GREINER* \\ Laboratory of Tumor Immunology and Biology, Center for Cancer Research, \\ National Cancer Institute, National Institutes of Health, Bethesda, MD, U.S.A.
}

\begin{abstract}
Investigation of the efficacy and mechanisms of human immuno-oncology agents has been hampered due to species-specific differences when utilizing preclinical mouse models. Peripheral blood mononuclear cell (PBMC) humanized mice provide a platform for investigating the modulation of the human immune-mediated antitumor response while circumventing the limitations of syngeneic model systems. Use of humanized mice has been stymied by model-specific limitations, some of which include the development of graft versus host disease, technical difficulty and cost associated with each humanized animal, and insufficient engraftment of some human immune subsets. Recent advances have addressed many of these limitations from which have emerged humanized models that are more clinically relevant. This review characterizes the expanded usage, advantages and limitations of humanized mice and provides insights into the development of the next generation of murine humanized models to further inform clinical applications of cancer immunotherapeutic agents.
\end{abstract}

The therapeutic landscape of cancer has expanded from radiation and chemotherapeutic intervention, and smallmolecule targeted agents to include immunotherapy, which can

This article is freely accessible online.

*These Authors contributed equally to this article.

Correspondence to: Jeffrey Schlom, Ph.D., Laboratory of Tumor Immunology and Biology, Center for Cancer Research, National Cancer Institute, 10 Center Drive, Room 8B09, Bethesda, MD 20892, U.S.A. Tel: +1 2408583463, Fax: +1 2405414558, e-mail: schlomj@mail.nih.gov

Key Words: PBMCs, humanized mice, immunotherapy, cancer, immuno-oncology, review. encompass adoptive cell transfer, gene therapy, both local and systemic immunostimulatory platforms, and modulation of immunosuppression (1-5). The inherent specificity of immunotherapeutics, while reducing off-target effects, often results in altered function or efficacy in murine models due to differences between human and murine immune systems $(6,7)$. Additionally, utilization of human biologics in wildtype mice can elicit an antibody-mediated mouse anti-human response, ultimately resulting in rapid clearance of a human therapeutic, which may alter or eliminate drug functionality within 4-7 days post-initiation of treatment $(8,9)$. In order to circumvent the mouse anti-human response, murine drug surrogates are often created; however, function and mechanism are not always identical to those of the original human drug. Further complicating the investigation of human therapeutics in syngeneic murine models are the inherent differences between murine and human immunity $(6,10)$. In order to overcome many of these limitations, humanized mouse models have been developed that utilize human tumors and immune cells. Humanized models allow for the in vivo investigation of modulating the human immune response utilizing human therapeutics to reduce human tumor burden in order to better bridge the gap between rodent models and the clinic.

\section{Humanized Mouse Overview}

Humanized mice are created when live human cells are introduced into an appropriate murine host. Engraftment of human cells into recipient mice elicits a xenogeneic response. Immunocompetent animals rapidly clear engrafted human tissue; as such, immunodeficient lines are utilized as recipients of human immune and tumor cells. Varying degrees of immunodeficiency result in different levels of graft acceptance and tolerance (Figure 1). The most commonly used recipient animals are those deficient in T- and B-cells via either the severe combined immunodeficiency (SCID) mutation or 
Murine MHC Deficiency

- Delayed development of GvHD

- Reduced T-cell exhaustion

- Reduced peripheral steady state IFN $\gamma$

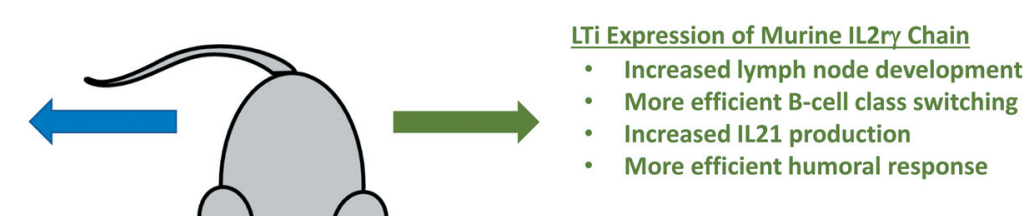

IL7 and IL15 Supplementation (Knock-in/Exogenous)

- Increased number of NK cell populations

- Increased activated NK cells

- Increased number of CD8+ T-cells

- Increased CD8+ T-cell activation

- Increased thymic output

Increased homeostatic expansion of T-cells

Addition of Species-specific Cytokines: GM-CSF, IL3, CSF, FLT3 ligand

- Increased MDSCs, macrophages, and DC populations

- Better myeloid engraftment, survival, and proliferation

- Increased overall human immune cell engraftment

Figure 1. Modifications and their effects on humanized mouse models. Genetic modifications of immunodeficient recipient mice result in better human immune engraftment, functionality, or resistance to graft versus host disease (GvHD). DC: Dendritic cells; GM-CSF: granulocytemacrophage colony-stimulating factor; IL: interleukin; LTi: lymphoid tissue inducer; MDSCs: myeloid-derived suppressor cells; NK: natural killer.

knockout of recombination-activating genes (RAG). Increased tolerance of human xenografts is obtained in animals also deficient in interleukin-2 receptor gamma chain (IL2r $\gamma$ ) function. IL2 $\gamma \gamma$ chain deficiency eliminates "leakiness" of the SCID mutation as well as natural killer (NK) and NK T-cell development. Mice deficient in IL2r $\gamma$ chain additionally lack IL2, IL4, IL7, IL9, IL15, and IL21 signaling (11, 12). Mice lacking T- and B-cells, and IL2r $\gamma$ are found on several backgrounds, including Balb/c and C57BL/6; however, the non-obese diabetic (NOD) mouse adds an additional level of immune tolerance, including CD47 polymorphisms (13), reduced compliment activity (14), as well as defective macrophage and dendritic cell (DC) function (15). The three most common murine lines used for the acceptance of human immune cells are: (a) NSG, which harbors the SCID mutation and knockout of Il2rg (16); (b) NRG, which exhibits knockout of Rag and II2rg chain genes (17); and (c) NOG, which harbors the SCID mutation and knockout of the cytoplasmic domain of IL2ry (18). While differences do exist among these three lines, they are functionally similar and can often be used interchangeably in humanized mouse studies. For the purposes of this review, we describe utilization and phenotypes observed in the NSG line; however, the description and relevance can also often be applied to both NRG and NOG lines.

There are three primary types of humanized murine models which are characterized by the method and type of cells utilized to engraft human immune cells: (a) Bone marrow, liver, thymus (BLT); (b) $\mathrm{CD}_{4} 4^{+} /$haematopoietic stem cells (HSCs); and (c) human peripheral blood mononuclear cells (PBMCs).

\section{BLT and CD34 $\%$ HSC Models}

The BLT model consists of transplantation of a small section of human fetal thymic and liver tissue under the kidney capsule of immunodeficient recipient mice, followed by injection of liver and/or bone marrow-derived autologous fetal CD $34^{+}$stem cells $(19,20)$.

The $\mathrm{CD} 34^{+} / \mathrm{HSC}$ model is created by injection of isolated human donor $\mathrm{CD} 4^{+}$cells from granulocyte colonystimulating factor mobilized peripheral blood, cord blood, or bone marrow aspirates into irradiated recipient mice $(21,22)$.

The BLT and HSC models exhibit a number of notable limitations, including: (a) Technical difficulty in creating each animal (19); (b) necessity to irradiate recipient animals, NOD mice are particularly sensitive to radiation (22); (c) expense; (d) necessity of human fetal tissue; (e) difficulty in using fresh/not frozen tissue (23); (f) difficulty in collecting materials from human donors; (g) 12 to 15 weeks required for animals to develop an adequate peripheral immune compartment (24); (h) deficient lymphoid structures (25); (i) incomplete myeloid compartment (26); and (j) inability to facilitate human B-cell class switching (27). Taken together, many of these challenges may limit widespread use and clinical relevance of the BLT and HSC models in the context of cancer immunotherapy.

\section{The PBMC Model}

The PBMC model consists of injection of gradient-isolated human PBMCs into recipient animals. A heterogenous 
population of immune cells that does not undergo isolation by magnetic or fluorescence-activated sorting is injected via intrasplenic, intraperitoneal, or intravenous route into recipient animals. One of the primary limiting factors in the PBMC model is the development of a lethal human antimouse graft versus host disease (GvHD), which will be discussed in more detail later. While some groups have noted a modest qualitative difference in the humanization process based on the route of PBMC engraftment, there is not a clear consensus as to which route - intrasplenic, intraperitoneal, or intravenous - is superior (22). The number of injected PBMCs varies based on the study; however, most groups report successful engraftment utilizing $5 \times 10^{6}-2 \times 10^{7}$ PBMCs per recipient mouse. Although functional differences have been reported when utilizing too few PBMCs (28), it is as yet unclear if there is an advantage or if acceleration of GvHD occurs when injecting larger numbers. Recipient animals may be irradiated or not, and while a phenotypic difference has been noted based on radiation status, a definitive advantage is either uncertain or likely contextual. It remains possible that in the PBMC model, circulating $\mathrm{CD}_{3} 4^{+}$cells from human donors are better able to engraft in irradiated recipients and additional haematopoietically derived subsets may have the opportunity to develop. Due to the longer time requirements of HSC engraftment and immune cell development, and the shorter lifespan of PBMC-engrafted mice, circulating donor $\mathrm{CD}_{3} 4^{+}$cells may have limited relevance in the PBMC model. Owing to the radiosensitivity of recipient NOD.scid mice (29) and the potential for accelerated GvHD, it is likely that avoiding irradiation may be preferred. PBMCs may be injected after freezing or injected fresh from human donors. While differences may be observed in some myeloid and B-cell lineages at the time of injection, appropriate freeze/thawing of adoptively transferred cells prior to injection does not appear to change survival or phenotypes of T-cells post engraftment $(28,30)$.

Advances in humanized mouse platforms for the investigation of clinical immunotherapeutic efficacy. One notable strength of the PBMC model is the ease and speed at which mice can be created and utilized. Circulating human immune cells are detected in recipient animals within 2 weeks post-PBMC engraftment, with an adequate peripheral human immune compartment being observed within 3 weeks (28). Some myeloid, NK, and NK T-cells remain for days to weeks but largely disappear as they lack appropriate survival signals, although exogenous or transgenic expression of various cytokines can aid in their survival (31). While B-cells expand and persist, they never reach human healthy donor frequencies (32). B-Cell class switching is limited; however, transferred plasma cells remain and produce human IgG (27).

Varying degrees of immune activity are observed in humanized mice within the immuno-oncology setting. Data support a model where varied antitumor activity is observed in response to immunomodulatory drugs that are dependent on the immune cell donor $(28,33)$. This varied response is consistent with results obtained in the clinic where most recipients of a therapeutic respond to varying degrees. These data support the likelihood that utilizing small numbers of immune donors in humanized immunooncology studies may not be representative of all or even most patient populations. In order to account for variation in donor PBMC response, multiple independent studies should be conducted utilizing different donor PBMCs. A large enough pool of donors would ensure that an observed effect would be drug- and not donor-specific. Few groups have used panels of HSC donors in order to examine a varied response at least due in part to the difficulty and expense in collecting CD $34^{+}$cells. The PBMC model has the advantage of being comparatively simple, fast, and inexpensive. Investigators are better able to confirm a general effect across multiple donors.

Human PBMCs injected into recipient mice rapidly expand due to a likely combination of homeostatic proliferation (34) and a xenogeneic response to murine antigens (35), which results in mice harboring physiologically relevant numbers of immune cells within 3 weeks post injection of human PBMCs $(28,35,36)$. In contrast, the HSC model requires months to develop equivalent levels of human immune engraftment. The rapid engraftment, and thus rapid availability of use, make the PBMC model feasible and accessible for use in personalized medicine, where a patient treatment regimen may be investigated in murine surrogates prior to being administered in the clinic. This approach is discussed later in more detail.

\section{Factors Affecting Immune Activity in Humanized Mice}

Individual patient responses to immunotherapeutic modulation may be dependent on a number of factors, including patient age, prior therapy, and the development of T-cell exhaustion. These factors should be taken into account in any investigation into immunotherapeutic efficacy. Each factor is discussed in detail below.

Patient age strongly influences the efficiency of an antitumor immune response. In the context of T-cells, phenotypic changes in thymic output, T-cell activity, and Tcell receptor repertoire usage and promiscuity are associated with age (37-40). As a result, HSC models that utilize a young thymus, whether human or mouse, may not produce clinically relevant T-cells for immuno-oncology studies, in which patients are skewed heavily towards older populations. In contrast, the PBMC model can recruit immune cell donors from older populations, which may be more representative of immune phenotypes in target demographics. 
Therapeutic modulation of the immune landscape can result in lasting changes to immune functionality. For example, chemotherapy may induce long-term changes in $\mathrm{CD}^{+} \mathrm{T}$-cell numbers, senescence, and efficiency of response $(41,42)$. Programmed cell death protein-1 (PD1) checkpoint inhibition can lead to therapeutic resistance to modulating the PD1-programmed cell death protein-1 ligand axis (43, 44). Additionally, patients who have undergone remission may have acquired specific immune phenotypes as a result of tumor clearance. Tumor progression after initial control may pose significant challenges in exploring and modeling future treatment options. PBMC humanized mice can utilize cells from donors who have experienced these clinical manifestations; as a result, researchers will be better able to investigate treatment options for these patient populations.

T-Cells undergoing chronic activation develop reduced immune activity and are identified by up-regulation of PD1, T-cell immunoglobulin and mucin-domain containing-3 (TIM3; hepatitis A virus cellular receptor 2), T-cell immunoreceptor with Ig and ITIM domains (TIGIT), and cytotoxic T-lymphocyte-associated protein 4 (CTLA4), among others $(45,46)$. Development of T-cell exhaustion has been shown to be an important mechanism of tumor escape; as such, much emphasis has been placed on reinvigorating the T-cell response to control tumor growth. In patient populations, T-cell exhaustion is frequently observed in the tumor microenvironment [reviewed in (47)], as well as subtle markers of T-cell exhaustion in the periphery (48). Humanized mice frequently develop exaggerated levels of Tcell exhaustion, which provide a larger target for immunotherapeutic modulation. In particular, the PBMC model offers greater up-regulation of markers of phenotypic exhaustion both in the tumor microenvironment and periphery $(28,49)$. Increased presence and faster upregulation of exhaustion markers assist in the ability to screen for effective immunomodulatory agents.

\section{Development of Humanized Mouse Models that Mitigate GvHD}

One of the challenges in developing humanized mouse models is the onset of GvHD and its influence on any biological measurement. Whether severe or mild, the development of GvHD is a state of active response and thus adds an additional variable to any line of investigation looking to modulate the immune response. The NSG, NRG, and NOG lines all natively express murine major histocompatibility complex (MHC), and in the presence of human T-cells restricted by human leukocyte antigen (HLA), such as in the PBMC and BLT models, a xeno-MHC mismatch occurs that drives GvHD development (50). CD8 ${ }^{+}$ T-cells mediate GvHD in PBMC humanized mice, while $\mathrm{CD}^{+} \mathrm{T}$-cells alone are not sufficient to cause this disease
(51). The HSC model relies on human T-cell selection and development in the murine thymus, resulting in T-cells likely restricted by murine $\mathrm{MHC}(50,52,53)$. The absence of a xeno-MHC mismatch in the HSC model likely confers a degree of tolerance and thus delays the development and severity of GvHD. The BLT model is engrafted with human thymic tissue, where human thymic epithelial cells are utilized to select and mature autologous thymocytes in vivo, resulting in T-cells restricted by human MHC. A number of factors likely play a role in tolerizing T-cells to murine epitopes, including human T-cell selection utilizing murine DCs as well as peripheral tolerance mechanisms (53). As discussed, tolerance in the HSC and BLT models is incomplete and GvHD eventually develops 24 weeks after engraftment of human tissues $(54,55)$.

The development of lethal GvHD is one of the primary limiting factors in humanized mouse models. NSG mice engrafted with human PBMC typically develop overt signs of acute GvHD beginning at 3-4 weeks post injection (56). A number of variants of the parental NSG, NRG, and NOG lines have been developed that eliminate murine MHC and delay onset of GvHD. NSG beta 2 microglobulin $(B 2 m)^{-/-}$ mouse, which is deficient in MHC class I via genetic deletion of $B 2 \mathrm{~m}$ gene, exhibits development of GvHD delayed by at least 2 weeks when compared to the parental NSG strain (28, 57). Associated with the deletion of $B 2 m$ is the absence of the neonatal Fc receptor $(\mathrm{FcRn})$, which results in reduced stability of circulating antibodies $(58,59)$ and should be considered in any study investigating the effects of antibodybased immunotherapeutics. Similarly, animals deficient in murine MHC class I, H2Kd and $\mathrm{H}-2 \mathrm{Db}$, have been created and have delayed development of GvHD in the presence of human PBMCs, without exhibiting reduced antibody stability. Mice deficient in MHC class I exhibit a reduced capacity to stimulate human $\mathrm{CD}^{+} \mathrm{T}$-cell proliferation (60), while still exhibiting high levels of CD8 activation (28). Similarly, animals deficient in murine MHC class II have lower capacity to stimulate human $\mathrm{CD}^{+}{ }^{+} \mathrm{T}$-cells $(60)$; however, they do not exhibit a delay in the development of GvHD (50). Animals deficient in both murine MHC class I (either via $\mathrm{B} 2 \mathrm{~m}$ or $\mathrm{Kd} / \mathrm{Db}$ ) and $\mathrm{MHC}$ class II exhibit a further delay and reduction of GvHD severity $(57,61)$. It has been noted that models injected with human PBMCs and deficient in murine MHC class I express constitutively high levels of circulating human interferon gamma (IFN $\gamma$ ); however, animals deficient in both murine MHC class I and II have much lower and more physiologically relevant levels (unpublished data). A recent study by Pyo et al. compared levels of serum cytokines from PBMC-engrafted parental NSG mice and their corresponding human donors (62). Cytokine levels were remarkably similar, with a few notable exceptions, including IFN $\gamma$, granulocyte-macrophage colony-stimulating factor (GM-CSF), and IL10. Complete characterization and 
comparison of the steady-state human and murine cytokine levels in PBMC-engrafted mice deficient in either or both murine MHC class I and II would be helpful in identifying models most relevant to a particular study.

Immunodeficient lines deficient in either murine $\mathrm{MHC}$ class I or II are better recipients of mature human PBMCs as a function of reduced and delayed development of GvHD. In contrast, MHC-deficient lines exhibit unique challenges in the HSC model. Mechanisms of central tolerance rely on thymocyte interactions with thymically expressed peptides and MHC $(63,64)$. In the HSC model, animals deficient in murine MHC class I are unable to produce mature human $\mathrm{CD}^{+} \mathrm{T}$-cells (65), likewise those animals not expressing murine MHC class II are unable to select mature human CD4 ${ }^{+}$T-cells (66). Presumably, human HSC-injected animals deficient in both murine MHC class I and II have greatly reduced numbers of circulating mature human T-cells. The BLT model does not rely on the endogenous murine thymus, and as such should have no defect in thymic output when utilizing MHC deficient recipient mice. As discussed, BLT mice slowly develop chronic GvHD; while not yet reported in the literature, the BLT model may benefit from utilizing MHC-deficient recipient animals by further delaying or eliminating GvHD.

\section{Possible Variations on the NSG/NRG/NOG Lines to Be Exploited in the PBMC Model for More Efficient Immune Cell Engraftment and Survival}

In addition to the development of GvHD, some humanized mouse models exhibit many important deficiencies, including: (a) Lack of efficient myeloid engraftment, (b) limited antigen-presenting cell activity, (c) poor NK and NK T-cell survival, (d) lack of lymph node and germinal center formation, (e) lack of B-cell class switching, and (f) low frequency of forkhead box protein P3 (FOXP3) regulatory T-cells. While many of these challenges have been addressed in the $\mathrm{CD} 4^{+} \mathrm{HSC}$ model utilizing novel variants of NSG/NRG/NOG mice, and are described here, there is a lack of published data investigating the effects of these novel lines in PBMC humanized models. Utilizing these transgenic lines may not completely correct the deficiencies noted in the PBMC model; it is likely, however, that they may improve and expand overall immune functionality to better model the human immune response and may be exploited to further investigate in vivo immunotherapeutic modulation for direct clinical benefit.

NK cells. NK cells are largely deficient from the parental NSG/NRG/NOG humanized mouse models primarily due to species specificity of both IL2 and IL15. Human and mouse IL15 share approximately 65\% homology (67), whereas murine IL2 has little effect on human cells (68). NK cells require constitutive IL2 for survival $(69,70)$ and IL15 for efficient activity and proliferation (71). Circulating T-cells from PBMC humanized models likely produce adequate amounts of IL2 for NK cell survival; the lack of a human myeloid compartment, however, results in insufficient human IL15 production and reduced NK cell numbers. In a study by Chen et al., exogenous expression of human IL15 via tail vein injected plasmid increased NK cell numbers and activity in the periphery of HSC engrafted mice. Importantly, exogenous expression of additional human cytokines increased myeloid cell frequency and function (72). Subsequently, the NSG hIL7/hIL15 knock-in mouse was recently produced that stably overcomes the lack of human IL15 (73) and increases the frequency and functionality of human NK cells following HSC engraftment.

There has been limited exploration of human IL15 supplementation in the PBMC model in the immunooncology setting; nevertheless, a recent study utilizing PBMC humanized mice in the HIV literature demonstrated increased perforin and granzyme production as well as NK lytic activity in response to an IL15 superagonist (74). While this study provides proof of concept that human NK activity and survival can be augmented via the addition of human IL15, the low frequency of NK cells in donor PBMCs might be a potential limiting factor in fully populating the NK compartment in humanized mice. Injection of either additional isolated autologous NK cells, or NK cell lines such as NK92 or high avidity NK (haNK) $(70,75,76)$, may assist in NK engraftment and investigation into activity in the immuno-oncology setting.

Myeloid cells. PBMC humanized mice display a low frequency of human myeloid cells, which is further reduced over time either due to senescence of the original population and failure to self-renew, or a lack of an appropriate cytokine milieu for survival and expansion. HSC engrafted NSG/NRG/NOG mice harbor some myeloid populations, albeit at lower than physiologically relevant levels. Low homology between murine and human cytokines necessary for survival of certain cellular subsets results in a necessity of species-specific cytokines such as GM-CSF, IL3, FMSrelated receptor tyrosine kinase 3 (FLT3) ligand, colonystimulating factor (CSF), IL2, and KIT ligand/Steel factor (SCF) $(77,78)$. Myeloid survival and proliferation can be rescued in HSC humanized mice via the addition of exogenous GM-CSF or FLT3 ligand $(79,80)$. Subsequently, several transgenic mouse lines have been designed to provide those necessary cytokines to enhance in vivo myeloid cell survival. The NSG-SGM3 mouse provides transgenic expression of human IL3, GM-CSF, and SCF. NSG-SGM3 animals engrafted with $\mathrm{CD} 34^{+}$cells isolated from cord blood develop more psychologically relevant numbers of human monocytes, granulocytes, neutrophils (81), DCs, regulatory 
T-cells (Tregs) (82), and NK cells $(83,84)$, all of which are normally greatly reduced in or absent from the engrafted parental NSG strain. Unfortunately, these animals frequently develop severe anemia/leukopenia, and exhibit progenitor cell exhaustion (81) and shortened survival and immune longevity. These adverse events may ultimately limit the use of $\mathrm{CD}_{3} 4^{+}$engrafted NSG-SGM3 mice in immuno-oncology studies. Alternatively, NSG-SGM3 animals engrafted with human PBMCs may have reduced development of anemia and leukopenia, although this may be attributed to the shortened life of PBMC-engrafted animals through the development of GvHD. Additionally, one would expect higher engraftment and survival of myeloid and FOXP3 Tregs in PBMC-engrafted NSG-SGM3 when compared with the engrafted parental NSG line. To date, this model has not been well characterized. A short-term comparison described few cellular differences between NSG and NSG-SGM3 animals engrafted with the same PBMC donor (85); however, the authors reported heightened and more clinically reflective cytokine production in PBMC engrafted NSG-SGM3 animals in response to immunotherapeutic modulation. With further investigation, immunotherapeutic modulation of PBMCengrafted NSG-SGM3 mice may provide a platform with which to investigate and predict the development of cytokinerelease syndrome using a humanized platform. Additionally, investigators characterized T-cell responses in PBMCengrafted NSG-SGM3 animals (86). While not in the immuno-oncology setting, the investigators reported modulated T-cell activation and IL17 production in the context of antiretroviral therapy and HIV infection.

An additional NOD line with high levels of myeloid cell development following $\mathrm{CD}_{3} 4^{+}$engraftment is the huNOGEXL model, which transgenically expresses human GM-CSF and IL3, while also harboring functional deletion of the IL2r $\gamma$ chain cytoplasmic domain (87). Phenotypes developing from CD34 engraftment are similar to those seen in the NSG-SGM3 model; however, a modest delay may exist in the development of anemia in the huNOG-EXL model, although a direct comparison utilizing identical donor material has yet to be described.

A similar line, termed the MISTRG, was created on the 129xBalb/c background harboring knockout of Rag2 and Il2rg while transgenically expressing human GM-CSF, CSF1, IL3, thrombopoietin (TPO), and signal-regulatory protein alpha (SIRPa) (88). Similar myelopoiesis to the NSG-SGM3 and huNOG-EXL lines was observed when engrafted with human $\mathrm{CD} 34^{+}$cells. The authors reported increased M2 macrophage infiltration, which they concluded contributes to increased growth of Me290 subcutaneous melanoma tumors. The contribution of either transgenically expressed human cytokines or increased presence of human myeloid cells and the role they play in tumor growth in humanized systems still need to be better characterized.
Additionally, further investigation may also elucidate additional mechanisms of tumor growth and identification of targets to exploit in the clinic.

Lack of lymph node development and B-cell class switching More recently, the NOG IL6 model was created (89), which exhibits myeloid development after CD $34^{+}$engraftment. The authors described increased myeloid-derived suppressor cell and tumor-associated macrophage development and infiltration into HSC4 subcutaneous tumors. HSC4 tumor growth was accelerated in NOG IL6 animals when compared with the NOG parental strain. The authors concluded this occurred as a direct effect of IL6 on tumor cells, although it remains possible that tumor-infiltrating lymphocytes may also contribute, as suggested in the MISTRG/Me290 model (88). Similarly, the MISTRG-6 mouse was created, which transgenically expresses human IL6 on the previously described MISTRG background. The authors described class switching and increased antigen-specific IgG production in response to peptide immunization in the HSC model (90).

One consequence of the murine I12rg chain knockout is a lack of lymph node development. A recent study described the development of a novel line termed the NOG-pROR $\gamma$ t$\gamma \mathrm{c} / \mathrm{GM} 3 \mathrm{Tg}$ mouse, wherein murine IL2r $\gamma$ is transgenically expressed in NOG mice under the lymphoid tissue inducerspecific retinoic acid receptor-related orphan receptor gamma $\mathrm{t}(\mathrm{ROR} \gamma \mathrm{t})$ promoter, in addition to transgenic expression of IL3 and GM-CSF. Localized expression of the murine IL2r $\gamma$ chain ultimately results in the development of lymph node architecture, which following HSC engraftment can be populated by human immune cells (91). In addition to the expected increased numbers of DC, macrophage, and NK cells, the authors noted increased $\mathrm{CD}^{+}{ }^{+}$IL21 production, as well as B-cell class switching and antigen-specific IgG production in response to vaccine. Further increased lymph node development was reported with the addition of transgenic expression of thymic stromal lymphopoietin; however, a high frequency of severe thymomas was also reported. While thymoma development will limit broad use, it may be interesting to determine if this phenotype can be exploited as a spontaneous humanized model for thymoma.

\section{Next-generation Humanized Models for Use in Personalized Medicine}

The evolution of humanized mouse models has accelerated in recent years. The addition of the $I l 2 \mathrm{rg}$ knockout to mouse lines deficient in B- and T-cells, such as the NSG/NRG/NOG lines, provided a more tolerant recipient mouse for accepting human xenografts. Models were further improved by removing murine MHC expression, which resulted in human immune xenografts being more tolerant to the murine host by delaying GvHD. The absence of murine MHC, however, 
does not completely prevent a xenogeneic response to murine tissues. A failure to recognize "self" via matched human MHC expression still leads to a mounting inflammatory response. Additional models have been created that have eliminated either murine MHC I or MHC class II, expressing human HLA class I or II in its place. Utilization of these lines in the immuno-oncology setting has been limited due to knockout and expression of either class I or II, which results in durable tolerance to only the single modified locus and the continued development of GvHD.

To date, a single mouse line, termed HUMAMICE, eliminates both murine MHC class I, via B2m knockout, and MHC class II, while simultaneously expressing HLA-A2 (class I) and HLA-DR1 (class II) (92) on the C57BL/6 background. HUMAMICE harbor a knockout for murine perforin, IL2r $\gamma$ chain, and are T- and B-cell deficient via Rag2 knockout. Efficient human T- and B-cell engraftment occurs post injection of human PBMCs without overt GvHD. Reported B-cell phenotypes in PBMC-engrafted HUMAMICE were moderately different from PBMCengrafted NSG mice. Increased frequency of B-cells capable of $\mathrm{IgG}$ production following vaccination with a hepatitis B vaccine was reported. Due to the limited number of PBMC donors used, it is unclear if these are donor- (i.e. previous antigen exposure) or model-specific phenotypes. While not reported, it would be interesting to introduce human $\mathrm{CD}_{3} 4^{+}$ HSCs into HUMAMICE to determine whether Tregs, and both $\mathrm{CD}^{+}$and $\mathrm{CD} 8^{+} \mathrm{T}$-cells restricted by human $\mathrm{MHC}$ class $\mathrm{I}$ and II can be de novo generated in the murine thymus. A number of caveats are likely present for HUMAMICE, including: (a) Being constructed on the C57BL/6 background does not exploit the previously discussed advantages of the NOD background in harboring xenografts; (b) $B 2 \mathrm{~m}^{-/-}$ results in reduced antibody stability, including of administered therapeutics; (c) although the authors did not report myeloid and NK engraftment, in the absence of the appropriate cytokine milieu, it is unlikely that these populations would differ from those of the NSG models; and (d) while $\mathrm{IgG}$ production was reported in response to hepatitis B virus vaccination, this may have been due to production via existing plasma cells from donor PBMCs and not class switching. Despite these limitations, HUMAMICE provide proof of concept that knockout of murine MHC I and II and subsequent expression of human HLA class I and II provide a platform for the generation of humanized mouse models that at a minimum better resist GvHD.

\section{Future Directions for PBMC Humanized Models}

Throughout this review we have described a constellation of genetic alterations that have improved or can improve humanized mouse models (Figure 1). Combinations of individual genetic modifications within a single mouse have proven efficacious in further improving models; for instance, adding IL6 expression to the MISTRG mouse enhanced the humoral response while maintaining myeloid engraftment of the MISTRG parental line (90). Additional combinations may prove beneficial in enhancing engraftment and performance in PBMC humanized models.

Further enhancement of the current PBMC mouse model may be achieved by incorporating expression of human class I and II HLA on the NSG MHC class I/II knockout background. This novel mouse may better resist GvHD when engrafted with MHC-matched PBMCs, express B2m/FcRN resulting in circulating antibody stability, harbor the NSG defective macrophage and DC compartment, and express the human immune-tolerant Sirpa polymorphism that is characteristic of the NOD background.

As discussed, the addition of human cytokine expression within PBMC humanized models has not thus far been reported to provide a demonstrative benefit; however, this may primarily be due to the limited number of reported investigations. A few studies have provided a glimpse into the benefits of utilizing human cytokines in PBMC humanized mouse models. For instance, the addition of an exogenous IL15 superagonist in PBMC-engrafted mice increased NK activation (74); however, changes in peripheral NK numbers were not reported. In an additional study, investigators transferred human PBMCs to NSG SGM3 mice, and reported T-cell activation and IL17 production, although no data were provided describing the effects on the myeloid compartment (86). Both the NK and myeloid compartments constitute a small fraction of what would have been initially engrafted; in the presence of the appropriate cytokine milieu it is likely though that increased survival of myeloid cells may be observed. Proliferation and expansion may remain deficient and an alternative approach to increasing numbers or expanding the NK and myeloid compartments may need to be explored. The addition of IL6 in PBMC humanized mice may aid in B-cell class switching and activity. Stable gene expression of the aforementioned cytokines would likely result in the most robust overall effect; however, injection of recombinant proteins (74) or transient vector-driven expression $(57,72)$ may yield a desired effect. Lastly, lymph node development through lymphoid tissue inducer-specific expression of the IL2 $\gamma \gamma$ chain may assist in appropriate antigen presentation and $\mathrm{T}$ cell priming in PBMC humanized mice.

Many of the initial limitations with humanized mouse models have begun to be addressed leading to more clinically relevant models. The field has reached a point where model specific artifacts have been reduced, resulting in a more accurate bridge between the clinic and murine models. Investigators have replicated patient outcomes to chemotherapeutics in patient-derived xenograft (PDX) recipient animals $(93,94)$, thus providing proof of concept 
that murine surrogates might predict patient-specific response. These studies open the door for a personalized medicine approach wherein murine surrogates might screen patient-specific response to identify more effective treatment options. Chemotherapeutic PDX tumor resistance has been confirmed to occur (95). Further investigation may help to determine if patient-specific resistance and escape may be modeled in murine surrogates to predict progression in the clinic and to identify second- and third-line treatment options. Limiting the use of PDX models in personalized medicine is a 4-8-month requirement to generate each patient-specific line (96). Many PDX attempts fail to generate a stable line, and while this may not reduce the utility of the platform when successful, it is an additional consideration when exploring approaches to personalized medicine. An additional caveat of PDX models is heterogeneity within patient tumors. Primary and metastatic sites exhibit varying degrees of therapeutic sensitivity, in addition to often dramatic differences within a particular tumor site [reviewed in (97)]. Variability may be difficult to model in a PDX system when a xenograft line is created from a small amount of tumor tissue.

To date, modeling patient-specific immune responses in murine models has been difficult. The CD34 and BLT models are less likely to be utilized in developing surrogates for personalized medicine due to many of the limitations listed early in this review, including difficulty in obtaining patient HSCs and the time required to establish a human immune system in recipient animals. PBMC models, while narrower in scope of immune engraftment, provide a more rapid model, when urgency may be a paramount consideration. It remains possible that exploiting many of the additional murine variant lines may broaden immune engraftment in the PBMC model and enhance relevance. Additionally, patient PBMCs can be easily obtained, with donor immune status at the time of collection remaining intact, thus providing a more clinically relevant model when compared to HSC-engrafted mice in which immune cells must become educated within the surrogate mouse.

Investigators have begun combining PDX tumors with patient-derived immune cells. This approach is being validated, where murine avatars are created and treated alongside their source patient $(98,99)$. These studies may provide insight into the interplay between tumor and autologous immune cells, providing additional mechanisms and targets to exploit for further clinical benefit. Continued development of this platform may present a new era of personalized medicine where a patient's disease state, including both tumor and immune profile, may be modeled in a murine surrogate. Conservation of both tumor and immune phenotypes may increase the likelihood of successful modulation of the patient's immune response, resulting in a more durable and robust response to treatment.

\section{Conclusion}

PBMC humanized mouse models provide an in vivo platform with which to investigate immunotherapeutic modulation of human immune cells and their needed machinery to facilitate the control or clearance of human tumors. Genetic enhancements of recipient mice have reduced model specific limitations while increasing physiological and clinical relevance. The humanized mouse platform continues to advance such that investigation of immunotherapeutics may become more predictive of clinical outcome, thus providing the possibility of utilizing humanized mice for more direct and personal patient care decisions.

\section{Conflicts of Interest}

The Authors have no conflicts of interest to declare.

\section{Authors' Contributions}

Writing of the article was performed by YMM, AS, and JWG. Review of the literature was performed by YMM, AS, and JWG. Review and approval of the article was performed by JWG and JS.

\section{Acknowledgements}

The Authors thank Debra Weingarten for her assistance in the preparation of this article. This study was supported by the Intramural Research Program of the Center for Cancer Research, National Cancer Institute, National Institutes of Health.

\section{References}

1 Das SK, Menezes ME, Bhatia S, Wang X-Y, Emdad L, Sarkar $\mathrm{D}$ and Fisher PB: Gene therapies for cancer: Strategies, challenges and successes. J Cell Physiol 230(2): 259-271, 2015. PMID: 25196387. DOI: 10.1002/jcp.24791

2 Iribarren K, Bloy N, Buqué A, Cremer I, Eggermont A, Fridman WH, Fucikova J, Galon J, Špíšek R, Zitvogel L, Kroemer G and Galluzzi L: Trial watch: immunostimulation with Toll-like receptor agonists in cancer therapy. Oncoimmunology 5(3): e1088631-e1088631, 2015. PMID: 27141345. DOI: 10.1080/ 2162402X.2015.1088631

3 Kamta J, Chaar M, Ande A, Altomare DA and Ait-Oudhia S: Advancing cancer therapy with present and emerging immunooncology approaches. Front Oncol 7: 64-64, 2017. PMID: 28459041. DOI: 10.3389/fonc.2017.00064

4 Morillon YM, 2nd, Hammond SA, Durham NM, Schlom J and Greiner JW: Enhanced immunotherapy by combining a vaccine with a novel murine GITR ligand fusion protein. Oncotarget 8(43): 73469-73482, 2017. PMID: 29088720. DOI: 10.18632/ oncotarget.20703

5 Wang M, Yin B, Wang HY and Wang R-F: Current advances in T-cell-based cancer immunotherapy. Immunotherapy 6(12): 1265-1278, 2014. PMID: 25524383. DOI: 10.2217/imt.14.86

6 Mestas J and Hughes CCW: Of mice and not men: Differences between mouse and human immunology. J Immunol 172(5): 
2731-2738, 2004. PMID: 14978070. DOI: 10.4049/jimmunol.172. 5.2731

7 Sathish JG, Sethu S, Bielsky M-C, de Haan L, French NS, Govindappa K, Green J, Griffiths CEM, Holgate S, Jones D, Kimber I, Moggs J, Naisbitt DJ, Pirmohamed M, Reichmann G, Sims J, Subramanyam M, Todd MD, Van Der Laan JW, Weaver RJ and Park BK: Challenges and approaches for the development of safer immunomodulatory biologics. Nat Rev Drug Discov 12(4): 306-324, 2013. PMID: 23535934. DOI: $10.1038 / \mathrm{nrd} 3974$

8 Myzithras M, Bigwarfe T, Li H, Waltz E, Ahlberg J, Giragossian $\mathrm{C}$ and Roberts S: Utility of immunodeficient mouse models for characterizing the preclinical pharmacokinetics of immunogenic antibody therapeutics. mAbs 8(8): 1606-1611, 2016. PMID: 27598372. DOI: $10.1080 / 19420862.2016 .1229721$

9 Ratanji KD, Derrick JP, Dearman RJ and Kimber I: Immunogenicity of therapeutic proteins: influence of aggregation. J Immunotoxicol 11(2): 99-109, 2014. PMID: 23919460. DOI: 10.3109/1547691X.2013.821564

10 Rongvaux A, Takizawa H, Strowig T, Willinger T, Eynon EE, Flavell RA and Manz MG: Human hemato-lymphoid system mice: current use and future potential for medicine. Annu Rev Immunol 31: 635-674, 2013. PMID: 23330956. DOI: 10.1146/ annurev-immunol-032712-095921

11 Notarangelo LD, Giliani S, Mazza C, Mella P, Savoldi G, Rodriguez-Pérez C, Mazzolari E, Fiorini M, Duse M, Plebani A, Ugazio AG, Vihinen M, Candotti F and Schumacher RF: Of genes and phenotypes: The immunological and molecular spectrum of combined immune deficiency. Defects of the gcJAK3 signaling pathway as a model. Immunol Rev 178(1): 3948, 2000. PMID: 11213805. DOI: 10.1034/j.1600-065X.2000. 17812.x

12 Rochman Y, Spolski R and Leonard WJ: New insights into the regulation of T cells by gamma(c) family cytokines. Nat Rev Immunol 9(7): 480-490, 2009. PMID: 19543225. DOI: $10.1038 /$ nri2580

13 Wong AS, Mortin-Toth S, Sung M, Canty AJ, Gulban O, Greaves DR and Danska JS: Polymorphism in the innate immune receptor SIRP $\alpha$ controls CD47 binding and autoimmunity in the nonobese diabetic mouse. J Immunol 193(10): 4833-4844, 2014. PMID: 25305319. DOI: 10.4049/jimmunol.1401984

14 Verma MK, Clemens J, Burzenski L, Sampson SB, Brehm MA, Greiner DL and Shultz LD: A novel hemolytic complementsufficient NSG mouse model supports studies of complementmediated antitumor activity in vivo. J Immunol Methods 446: 47-53, 2017. PMID: 28390927. DOI: 10.1016/j.jim.2017.03.021

15 Pearson T, Markees TG, Serreze DV, Pierce MA, Marron MP, Wicker LS, Peterson LB, Shultz LD, Mordes JP, Rossini AA and Greiner DL: Genetic disassociation of autoimmunity and resistance to costimulation blockade-induced transplantation tolerance in nonobese diabetic mice. J Immunol 171(1): 185195, 2003. PMID: 12816997. DOI: 10.4049/jimmunol.171.1.185

16 Ito M, Hiramatsu H, Kobayashi K, Suzue K, Kawahata M, Hioki K, Ueyama Y, Koyanagi Y, Sugamura K, Tsuji K, Heike T and Nakahata T: NOD/SCID/ $\gamma$ cnull mouse: An excellent recipient mouse model for engraftment of human cells. Blood 100(9): 3175-3182, 2002. PMID: 12384415. DOI: 10.1182/ blood-2001-12-0207

17 Pearson T, Shultz LD, Miller D, King M, Laning J, Fodor W, Cuthbert A, Burzenski L, Gott B, Lyons B, Foreman O, Rossini
AA and Greiner DL: Non-obese diabetic-recombination activating gene-1 (NOD-Rag1 null) interleukin (IL)-2 receptor common gamma chain (IL2r gamma null) null mice: A radioresistant model for human lymphohaematopoietic engraftment. Clin Exp Immunol 154(2): 270-284, 2008. PMID: 18785974. DOI: 10.1111/j.1365-2249.2008.03753.x

18 Ohbo K, Suda T, Hashiyama M, Mantani A, Ikebe M, Miyakawa K, Moriyama M, Nakamura M, Katsuki M, Takahashi K, Yamamura K and Sugamura K: Modulation of hematopoiesis in mice with a truncated mutant of the interleukin-2 receptor gamma chain. Blood 87(3): 956-967, 1996. PMID: 8562967.

19 Aryee K-E, Shultz LD and Brehm MA: Immunodeficient mouse model for human hematopoietic stem cell engraftment and immune system development. In: Hematopoietic Stem Cell Protocols. Bunting KD and Qu C-K (eds.). Springer New York: New York, NY, pp. 267-278, 2014.

20 Covassin L, Jangalwe S, Jouvet N, Laning J, Burzenski L, Shultz LD and Brehm MA: Human immune system development and survival of non-obese diabetic (NOD)-scid IL2rynull (NSG) mice engrafted with human thymus and autologous haematopoietic stem cells. Clin Exp Immunol 174(3): 372-388, 2013. PMID: 23869841. DOI: 10.1111/cei.12180

21 Brehm MA, Cuthbert A, Yang C, Miller DM, DiIorio P, Laning J, Burzenski L, Gott B, Foreman O, Kavirayani A, Herlihy M, Rossini AA, Shultz LD and Greiner DL: Parameters for establishing humanized mouse models to study human immunity: analysis of human hematopoietic stem cell engraftment in three immunodeficient strains of mice bearing the IL2rgamma(null) mutation. Clin Immunol 135(1): 84-98, 2010. PMID: 20096637. DOI: 10.1016/j.clim.2009.12.008

22 Pearson T, Greiner DL and Shultz LD: Creation of "humanized" mice to study human immunity. Curr Protoc Immunol Chapter 15: Unit-15.21, 2008. PMID: 18491294. DOI: 10.1002/047 1142735.im1521s81

23 Meraz IM, Majidi M, Meng F, Shao R, Ha MJ, Neri S, Fang B, Lin SH, Tinkey PT, Shpall EJ, Morris J and Roth JA: An improved patient-derived xenograft humanized mouse model for evaluation of lung cancer immune responses. Cancer Immunol Res 7(8): 1267-1279, 2019. PMID: 31186248. DOI: 10.1158/2326-6066.CIR-18-0874

24 Cheng L, Ma J, Li G and Su L: Humanized mice engrafted with human HSC only or HSC and thymus support comparable HIV1 replication, immunopathology, and responses to ART and immune therapy. Front Immunol 9: 817-817, 2018. PMID: 29725337. DOI: $10.3389 /$ fimmu.2018.00817

25 Brehm MA, Shultz LD, Luban J and Greiner DL: Overcoming current limitations in humanized mouse research. J Infect Dis 208 Suppl 2(Suppl 2): S125-S130, 2013. PMID: 24151318. DOI: 10.1093/infdis/jit319

26 Shultz LD, Lyons BL, Burzenski LM, Gott B, Chen X, Chaleff S, Kotb M, Gillies SD, King M, Mangada J, Greiner DL and Handgretinger R: Human lymphoid and myeloid cell development in NOD/LtSz-scid IL2R $\gamma$ null mice engrafted with mobilized human hemopoietic stem cells. J Immunol 174(10): 6477-6489, 2005. PMID: 15879151. DOI: 10.4049/jimmunol.174.10.6477

27 Ishikawa Y, Usui T, Shiomi A, Shimizu M, Murakami K and Mimori T: Functional engraftment of human peripheral $\mathrm{T}$ and $\mathrm{B}$ cells and sustained production of autoantibodies in NOD/ LtSzscid/IL-2R $\gamma(-/-)$ mice. Eur J Immunol 44(11): 3453-3463, 2014. PMID: 25154613. DOI: 10.1002/eji.201444729 
28 Morillon YM, II, Smalley Rumfield C, Pellom ST, Sabzevari A, Roller NT, Horn LA, Jochems C, Palena C, Greiner JW and Schlom J: The use of a humanized NSG- $\beta 2 \mathrm{~m}-/-$ model for investigation of immune and anti-tumor effects mediated by the bifunctional immunotherapeutic bintrafusp alfa. Front Oncol 10: 549, 2020. PMID: 32373533. DOI: 10.3389/fonc.2020.00549

29 Shultz LD, Lang PA, Christianson SW, Gott B, Lyons B, Umeda S, Leiter E, Hesselton R, Wagar EJ, Leif JH, Kollet Ó, Lapidot $\mathrm{T}$ and Greiner DL: NOD/LtSz-Raglnull mice: an immunodeficient and radioresistant model for engraftment of human hematolymphoid cells, HIV infection, and adoptive transfer of NOD mouse diabetogenic T cells. J Immunol 164(5): 2496-2507, 2000. DOI: 10.4049/jimmunol.164.5.2496

30 Ali N, Flutter B, Sanchez Rodriguez R, Sharif-Paghaleh E, Barber LD, Lombardi G and Nestle FO: Xenogeneic graftversus-host-disease in NOD-scid IL-2R $\gamma$ null mice display a Teffector memory phenotype. PLoS One 7(8): e44219, 2012. PMID: 22937164. DOI: 10.1371/journal.pone.0044219

31 Yong KSM, Her Z and Chen Q: Humanized mice as unique tools for human-specific studies. Arch Immunol Ther Exp 66(4): 245266, 2018. PMID: 29411049. DOI: 10.1007/s00005-018-0506-x

32 Lang J, Kelly M, Freed BM, McCarter MD, Kedl RM, Torres RM and Pelanda R: Studies of lymphocyte reconstitution in a humanized mouse model reveal a requirement of $\mathrm{T}$ cells for human B cell maturation. J Immunol 190(5): 2090-2101, 2013. PMID: 23335750. DOI: 10.4049/jimmunol.1202810

33 Wang M, Yao L-C, Cheng M, Cai D, Martinek J, Pan C-X, Shi W, Ma A-H, De Vere White RW, Airhart S, Liu ET, Banchereau J, Brehm MA, Greiner DL, Shultz LD, Palucka K and Keck JG: Humanized mice in studying efficacy and mechanisms of PD-1targeted cancer immunotherapy. FASEB J 32(3): 1537-1549, 2018. PMID: 29146734. DOI: 10.1096/fj.201700740R

34 Onoe T, Kalscheuer H, Chittenden M, Zhao G, Yang Y-G and Sykes M: Homeostatic expansion and phenotypic conversion of human $\mathrm{T}$ cells depend on peripheral interactions with APCs. J Immunol 184(12): 6756-6765, 2010. PMID: 20483739. DOI: 10.4049/jimmunol.0901711

35 Yaguchi T, Kobayashi A, Inozume T, Morii K, Nagumo H, Nishio H, Iwata T, Ka Y, Katano I, Ito R, Ito M and Kawakami Y: Human PBMC-transferred murine MHC class I/II-deficient NOG mice enable long-term evaluation of human immune responses. Cell Mol Immunol 15(11): 953-962, 2018. PMID: 29151581. DOI: $10.1038 / \mathrm{cmi} .2017 .106$

36 Kim KC, Choi B-S, Kim K-C, Park KH, Lee HJ, Cho YK, Kim SI, Kim SS, Oh Y-K and Kim YB: A simple mouse model for the study of human immunodeficiency virus. AIDS Res Hum Retroviruses 32(2): 194-202, 2016. PMID: 26564392. DOI: 10.1089/AID.2015.0211

37 Czesnikiewicz-Guzik M, Lee W-W, Cui D, Hiruma Y, Lamar DL, Yang Z-Z, Ouslander JG, Weyand CM and Goronzy JJ: T cell subset-specific susceptibility to aging. Clin Immunol 127(1): 107118, 2008. PMID: 18222733. DOI: 10.1016/j.clim.2007.12.002

38 Haynes L and Maue AC: Effects of aging on T cell function. Curr Opin Immunol 21(4): 414-417, 2009. PMID: 19500967. DOI: $10.1016 /$ j.coi.2009.05.009

39 He Q, Morillon YM, 2nd, Spidale NA, Kroger CJ, Liu B, Sartor RB, Wang B and Tisch R: Thymic development of autoreactive $\mathrm{T}$ cells in NOD mice is regulated in an age-dependent manner. J Immunol 191(12): 5858-5866, 2013. PMID: 24198282. DOI: $10.4049 /$ jimmunol.1302273
40 Ventura MT, Casciaro M, Gangemi S and Buquicchio R: Immunosenescence in aging: between immune cells depletion and cytokines up-regulation. Clin Mol Allergy 15: 21-21, 2017. PMID: 29259496. DOI: 10.1186/s12948-017-0077-0

41 Fane $\mathrm{M}$ and Weeraratna AT: How the ageing microenvironment influences tumour progression. Nat Rev Cancer 20(2): 89-106, 2020. PMID: 31836838. DOI: 10.1038/s41568-019-0222-9

42 Onyema OO, Decoster L, Njemini R, Forti LN, Bautmans I, De Waele $\mathrm{M}$ and Mets T: Shifts in subsets of $\mathrm{CD} 8^{+} \mathrm{T}$-cells as evidence of immunosenescence in patients with cancers affecting the lungs: An observational case-control study. BMC Cancer 15: 1016-1016, 2015. PMID: 26711627. DOI: 10.1186/s12885-0152013-3

43 Barrueto L, Caminero F, Cash L, Makris C, Lamichhane P and Deshmukh RR: Resistance to checkpoint inhibition in cancer immunotherapy. Transl Oncol 13(3): 100738-100738, 2020. PMID: 32114384. DOI: 10.1016/j.tranon.2019.12.010

44 Zaretsky JM, Garcia-Diaz A, Shin DS, Escuin-Ordinas H, Hugo W, Hu-Lieskovan S, Torrejon DY, Abril-Rodriguez G, Sandoval S, Barthly L, Saco J, Homet Moreno B, Mezzadra R, Chmielowski B, Ruchalski K, Shintaku IP, Sanchez PJ, PuigSaus C, Cherry G, Seja E, Kong X, Pang J, Berent-Maoz B, Comin-Anduix B, Graeber TG, Tumeh PC, Schumacher TN, Lo RS and Ribas A: Mutations associated with acquired resistance to PD-1 blockade in melanoma. N Engl J Med 375(9): 819-829, 2016. PMID: 27433843. DOI: 10.1056/NEJMoa1604958

45 Anderson AC, Joller N and Kuchroo VK: Lag-3, Tim-3, and TIGIT: Co-inhibitory receptors with specialized functions in immune regulation. Immunity 44(5): 989-1004, 2016. PMID: 27192565. DOI: 10.1016/j.immuni.2016.05.001

46 Qin S, Xu L, Yi M, Yu S, Wu K and Luo S: Novel immune checkpoint targets: moving beyond PD-1 and CTLA-4. Mol Cancer 18(1): 155, 2019. PMID: 31690319. DOI: 10.1186/s12943-019-1091-2

47 Davoodzadeh Gholami M, kardar GA, Saeedi Y, Heydari S, Garssen $\mathbf{J}$ and Falak R: Exhaustion of T lymphocytes in the tumor microenvironment: Significance and effective mechanisms. Cell Immunol 322: 1-14, 2017. PMID: 29079339. DOI: $10.1016 /$ j.cellimm.2017.10.002

48 Haymaker C, Wu R, Bernatchez C and Radvanyi L: PD-1 and BTLA and CD8(+) T-cell "exhaustion" in cancer: "Exercising" an alternative viewpoint. OncoImmunology 1(5): 735-738, 2012. PMID: 22934265. DOI: 10.4161/onci.20823

49 Lin S, Huang G, Cheng L, Li Z, Xiao Y, Deng Q, Jiang Y, Li B, Lin S, Wang S, Wu Q, Yao H, Cao S, Li Y, Liu P, Wei W, Pei D, Yao Y, Wen Z, Zhang X, Wu Y, Zhang Z, Cui S, Sun X, Qian X and Li P: Establishment of peripheral blood mononuclear cellderived humanized lung cancer mouse models for studying efficacy of PD-L1/PD-1 targeted immunotherapy. mAbs 10(8): 1301-1311, 2018. PMID: 30204048. DOI: 10.1080/19420 862.2018.1518948

50 King MA, Covassin L, Brehm MA, Racki W, Pearson T, Leif J, Laning J, Fodor W, Foreman O, Burzenski L, Chase TH, Gott B, Rossini AA, Bortell R, Shultz LD and Greiner DL: Human peripheral blood leucocyte non-obese diabetic-severe combined immunodeficiency interleukin-2 receptor gamma chain gene mouse model of xenogeneic graft-versus-host-like disease and the role of host major histocompatibility complex. Clin Exp Immunol 157(1): 104-118, 2009. PMID: 19659776. DOI: 10.1111/j.1365-2249.2009.03933.x 
51 Søndergaard H, Kvist PH and Haase C: Human T cells depend on functional calcineurin, tumour necrosis factor- $\alpha$ and CD80/CD86 for expansion and activation in mice. Clin Exp Immunol 172(2): 300-310, 2013. PMID: 23574326. DOI: 10.1111/cei.12051

52 Covassin L, Laning J, Abdi R, Langevin DL, Phillips NE, Shultz LD and Brehm MA: Human peripheral blood CD4 T cellengrafted non-obese diabetic-scid IL2rynull H2-Ab1 tm1Gru Tg (human leucocyte antigen D-related 4) mice: A mouse model of human allogeneic graft-versus-host disease. Clin Exp Immunol 166(2): 269-280, 2011. PMID: 21985373. DOI: 10.1111/j.13652249.2011.04462.x

53 Watanabe Y, Takahashi T, Okajima A, Shiokawa M, Ishii N, Katano I, Ito R, Ito M, Minegishi M, Minegishi N, Tsuchiya S and Sugamura K: The analysis of the functions of human B and $\mathrm{T}$ cells in humanized NOD/shi-scid/gammac(null) (NOG) mice (hu-HSC NOG mice). Int Immunol 21(7): 843-858, 2009. PMID: 19515798. DOI: 10.1093/intimm/dxp050

54 Greenblatt MB, Vrbanac V, Tivey T, Tsang K, Tager AM and Aliprantis AO: Graft versus host disease in the bone marrow, liver and thymus humanized mouse model. PLoS One 7(9): e44664, 2012. PMID: 22957096. DOI: 10.1371/journal.pone. 0044664

55 Sonntag K, Eckert F, Welker C, Müller H, Müller F, Zips D, Sipos B, Klein R, Blank G, Feuchtinger T, Schumm M, Handgretinger R and Schilbach K: Chronic graft-versus-hostdisease in CD34(+)-humanized NSG mice is associated with human susceptibility HLA haplotypes for autoimmune disease. J Autoimmun 62: 55-66, 2015. PMID: 26143958. DOI: 10.1016/j.jaut.2015.06.006

56 Lockridge JL, Zhou Y, Becker YA, Ma S, Kenney SC, Hematti P, Capitini CM, Burlingham WJ, Gendron-Fitzpatrick A and Gumperz JE: Mice engrafted with human fetal thymic tissue and hematopoietic stem cells develop pathology resembling chronic graft-versus-host disease. Biol Blood Marrow Transplant 19(9): 1310-1322, 2013. PMID: 23806772. DOI: 10.1016/j.bbmt.2013.06.007

57 Brehm MA, Kenney LL, Wiles MV, Low BE, Tisch RM, Burzenski L, Mueller C, Greiner DL and Shultz LD: Lack of acute xenogeneic graft- versus-host disease, but retention of Tcell function following engraftment of human peripheral blood mononuclear cells in NSG mice deficient in MHC class I and II expression. FASEB J 33(3): 3137-3151, 2019. PMID: 30383447. DOI: $10.1096 / f j .201800636 R$

58 Pyzik M, Sand KMK, Hubbard JJ, Andersen JT, Sandlie I and Blumberg RS: The neonatal $\mathrm{Fc}$ receptor $(\mathrm{FcRn})$ : A misnomer? Front Immunol 10: 1540-1540, 2019. PMID: 31354709. DOI: 10.3389/fimmu.2019.01540

59 Roopenian DC and Akilesh S: FcRn: the neonatal Fc receptor comes of age. Nat Rev Immunol 7(9): 715-725, 2007. PMID: 17703228. DOI: $10.1038 /$ nri2155

60 Pino S, Brehm MA, Covassin-Barberis L, King M, Gott B, Chase TH, Wagner J, Burzenski L, Foreman O, Greiner DL and Shultz LD: Development of novel major histocompatibility complex class I and class II-deficient NOD-SCID IL2R gamma chain knockout mice for modeling human xenogeneic graftversus-host disease. Methods Mol Biol 602: 105-117, 2010. PMID: 20012395. DOI: 10.1007/978-1-60761-058-8_7

61 Ashizawa T, Iizuka A, Nonomura C, Kondou R, Maeda C, Miyata H, Sugino T, Mitsuya K, Hayashi N, Nakasu Y,
Maruyama K, Yamaguchi K, Katano I, Ito M and Akiyama Y: Antitumor effect of programmed death-1 (PD-1) blockade in humanized the NOG-MHC double knockout mouse. Clin Cancer Res 23(1): 149-158, 2017. PMID: 27458246. DOI: 10.1158/1078-0432.CCR-16-0122

62 Pyo KH, Kim JH, Lee J-M, Kim SE, Cho JS, Lim SM and Cho $\mathrm{BC}$ : Promising preclinical platform for evaluation of immunooncology drugs using Hu-PBL-NSG lung cancer models. Lung Cancer 127: 112-121, 2019. DOI: 10.1016/j.lungcan.2018.11.035

63 Xing $\mathrm{Y}$ and Hogquist KA: T-cell tolerance: central and peripheral. Cold Spring Harb Perspect Biol 4(6): a006957, 2012. PMID: 22661634. DOI: 10.1101/cshperspect.a006957

64 Adamopoulou E, Tenzer S, Hillen N, Klug P, Rota IA, Tietz S, Gebhardt M, Stevanovic S, Schild H, Tolosa E, Melms A and Stoeckle C: Exploring the MHC-peptide matrix of central tolerance in the human thymus. Nat Commun 4(1): 2039, 2013. DOI: $10.1038 /$ ncomms 3039

65 André MC, Erbacher A, Gille C, Schmauke V, Goecke B, Hohberger A, Mang P, Wilhelm A, Mueller I, Herr W, Lang P, Handgretinger R and Hartwig UF: Long-term human CD34+ stem cell-engrafted nonobese diabetic/SCID/IL-2R gamma(null) mice show impaired $\mathrm{CD} 8^{+} \mathrm{T}$ cell maintenance and a functional arrest of immature NK cells. J Immunol 185(5): 2710-2720, 2010. PMID: 20668220. DOI: 10.4049/jimmunol.1000583

66 Grusby MJ and Glimcher LH: Immune responses in MHC class II-deficient mice. Annu Rev Immunol 13: 417-435, 1995. PMID: 7612230. DOI: 10.1146/annurev.iy.13.040195.002221

67 Anderson DM, Kumaki S, Ahdieh M, Bertles J, Tometsko M, Loomis A, Giri J, Copeland NG, Gilbert DJ, Jenkins NA, Valentine V, Shapiro DN, Morris SW, Park LS and Cosman D: Functional characterization of the human interleukin-15 receptor alpha chain and close linkage of IL15RA and IL2RA genes. J Biol Chem 270(50): 29862-29869, 1995. PMID: 8530383. DOI: $10.1074 / j b c .270 .50 .29862$

68 Mosmann TR, Yokota T, Kastelein R, Zurawski SM, Arai N and Takebe Y: Species-specificity of $\mathrm{T}$ cell stimulating activities of IL 2 and BSF-1 (IL 4): comparison of normal and recombinant, mouse and human IL 2 and BSF-1 (IL 4). J Immunol 138(6): 1813-1816, 1987. PMID: 3493289.

69 Meazza R, Azzarone B, Orengo AM and Ferrini S: Role of common-gamma chain cytokines in NK cell development and function: perspectives for immunotherapy. J Biomed Biotechnol 2011: 861920-861920, 2011. PMID: 21716670. DOI: 10.1155/ $2011 / 861920$

70 Tam YK, Maki G, Miyagawa B, Hennemann B, Tonn T and Klingemann HG: Characterization of genetically altered, interleukin 2-independent natural killer cell lines suitable for adoptive cellular immunotherapy. Hum Gene Ther 10(8): 13591373, 1999. DOI: 10.1089/10430349950018030

71 Kennedy MK, Glaccum M, Brown SN, Butz EA, Viney JL, Embers M, Matsuki N, Charrier K, Sedger L, Willis CR, Brasel K, Morrissey PJ, Stocking K, Schuh JC, Joyce S and Peschon JJ: Reversible defects in natural killer and memory CD8 T cell lineages in interleukin 15-deficient mice. J Exp Med 191(5): 771-780, 2000. PMID: 10704459. DOI: 10.1084/jem.191.5.771

72 Chen Q, Khoury M and Chen J: Expression of human cytokines dramatically improves reconstitution of specific human-blood lineage cells in humanized mice. Proc Natl Acad Sci USA 106(51): 21783-21788, 2009. PMID: 19966223. DOI: $10.1073 /$ pnas. 0912274106 
73 Matsuda M, Ono R, Iyoda T, Endo T, Iwasaki M, TomizawaMurasawa M, Saito Y, Kaneko A, Shimizu K, Yamada D, Ogonuki N, Watanabe T, Nakayama M, Koseki Y, KezukaShiotani F, Hasegawa T, Yabe H, Kato S, Ogura A, Shultz LD, Ohara O, Taniguchi M, Koseki H, Fujii S-I and Ishikawa F: Human NK cell development in hIL-7 and hIL-15 knockin NOD/SCID/IL2rgKO mice. Life Sci Alliance 2(2): e201800195, 2019. PMID: 30936185 . DOI: $10.26508 / 1$ sa.201800195

74 Seay K, Church C, Zheng JH, Deneroff K, Ochsenbauer C, Kappes JC, Liu B, Jeng EK, Wong HC and Goldstein H: In vivo activation of human NK cells by treatment with an interleukin15 superagonist potently inhibits acute in vivo HIV-1 infection in humanized mice. J Virol 89(12): 6264-6274, 2015. PMID: 25833053. DOI: $10.1128 /$ jvi.00563-15

75 Geller MA and Miller JS: Use of allogeneic NK cells for cancer immunotherapy. Immunotherapy 3(12): 1445-1459, 2011. PMID: 22091681. DOI: 10.2217/imt.11.131

76 Jochems C, Hodge JW, Fantini M, Fujii R, Morillon YM, 2nd, Greiner JW, Padget MR, Tritsch SR, Tsang KY, Campbell KS, Klingemann H, Boissel L, Rabizadeh S, Soon-Shiong P and Schlom J: An NK cell line (haNK) expressing high levels of granzyme and engineered to express the high affinity CD16 allele. Oncotarget 7(52): 86359-86373, 2016. PMID: 27861156. DOI: $10.18632 /$ oncotarget.13411

77 Shanafelt AB, Johnson KE and Kastelein RA: Identification of critical amino acid residues in human and mouse granulocytemacrophage colony-stimulating factor and their involvement in species specificity. J Biol Chem 266(21): 13804-13810, 1991. PMID: 1856212.

78 Tsapogas P, Mooney CJ, Brown G and Rolink A: The cytokine Flt3-ligand in normal and malignant hematopoiesis. Int J Mol Sci 18(6): 1115, 2017. PMID: 28538663. DOI: 10.3390/ ijms 18061115

79 Ding Y, Wilkinson A, Idris A, Fancke B, O’Keeffe M, Khalil D, Ju X, Lahoud MH, Caminschi I, Shortman K, Rodwell R, Vuckovic $S$ and Radford KJ: FLT3-ligand treatment of humanized mice results in the generation of large numbers of CD141+ and CD1c+ dendritic cells in vivo. J Immunol 192(4): 1982-1989, 2014. PMID: 24453245. DOI: 10.4049/jimmunol. 1302391

80 Iwabuchi R, Ikeno S, Kobayashi-Ishihara M, Takeyama H, Ato $\mathrm{M}$, Tsunetsugu-Yokota $\mathrm{Y}$ and Terahara K: Introduction of human Flt3-L and GM-CSF into humanized mice enhances the reconstitution and maturation of myeloid dendritic cells and the development of Foxp3(+)CD4(+) T-cells. Front Immunol 9: 1042, 2018. PMID: 29892279. DOI: 10.3389/fimmu.2018.01042

81 Coughlan AM, Harmon C, Whelan S, O'Brien EC, O'Reilly VP, Crotty P, Kelly P, Ryan M, Hickey FB, O'Farrelly C and Little MA: Myeloid engraftment in humanized mice: Impact of granulocyte-colony stimulating factor treatment and transgenic mouse strain. Stem Cells Dev 25(7): 530-541, 2016. PMID: 26879149. DOI: $10.1089 / \mathrm{scd} .2015 .0289$

82 Billerbeck E, Barry WT, Mu K, Dorner M, Rice CM and Ploss A: Development of human CD4+FoxP3+ regulatory $\mathrm{T}$ cells in human stem cell factor-, granulocyte-macrophage colonystimulating factor-, and interleukin-3-expressing NOD-SCID IL2R $\gamma($ null) humanized mice. Blood 117(11): 3076-3086, 2011. PMID: 21252091. DOI: 10.1182/blood-2010-08-301507

83 Beyer AI and Muench MO: Comparison of human hematopoietic reconstitution in different strains of immunodeficient mice. Stem
Cells Dev 26(2): 102-112, 2017. PMID: 27758159. DOI: 10.1089/scd.2016.0083

84 Wunderlich M, Chou F-S, Sexton C, Presicce P, Chougnet CA, Aliberti $\mathrm{J}$ and Mulloy JC: Improved multilineage human hematopoietic reconstitution and function in NSGS mice. PloS One 13(12): e0209034-e0209034, 2018. PMID: 30540841. DOI: 10.1371/journal.pone.0209034

85 Ye C, Brehm M, Cheng M, Shultz L, Greiner D and Keck J: Increased sensitivity for detecting cytokine release syndrome with cancer immunotherapy using a PBMC humanized NSGSGM3 mouse model (abstr 3902). Proceedings of the 2019 American Association for Cancer Research (AACR) Annual Meeting, March 29-April 3, 2019, Atlanta, GA Cancer Res 79(13 Suppl), 2019.

86 Perdomo-Celis F, Medina-Moreno S, Davis H, Bryant J, Taborda NA, Rugeles MT, Kottilil S and Zapata JC: High activation and skewed $\mathrm{T}$ cell differentiation are associated with low IL-17A levels in a hu-PBL-NSG-SGM3 mouse model of HIV infection. Clin Exp Immunol 200(2): 185-198, 2020. PMID: 31951011. DOI: $10.1111 /$ cei.13416

87 Ito R, Takahashi T, Katano I, Kawai K, Kamisako T, Ogura T, Ida-Tanaka M, Suemizu H, Nunomura S, Ra C, Mori A, Aiso S and Ito M: Establishment of a human allergy model using human IL-3/GM-CSF-transgenic NOG mice. J Immunol 191(6): 28902899, 2013. DOI: 10.4049/jimmunol.1203543

88 Rongvaux A, Willinger T, Martinek J, Strowig T, Gearty SV, Teichmann LL, Saito Y, Marches F, Halene S, Palucka AK, Manz MG and Flavell RA: Development and function of human innate immune cells in a humanized mouse model. Nat Biotechnol 32(4): 364-372, 2014. PMID: 24633240. DOI: $10.1038 /$ nbt. 2858

89 Hanazawa A, Ito R, Katano I, Kawai K, Goto M, Suemizu H, Kawakami Y, Ito $\mathrm{M}$ and Takahashi T: Generation of human immunosuppressive myeloid cell populations in human interleukin-6 transgenic NOG mice. Front Immunol 9: 152, 2018. DOI: $10.3389 /$ fimmu.2018.00152

$90 \mathrm{Yu} \mathrm{H}$, Borsotti C, Schickel JN, Zhu S, Strowig T, Eynon EE, Frleta D, Gurer C, Murphy AJ, Yancopoulos GD, Meffre E, Manz MG and Flavell RA: A novel humanized mouse model with significant improvement of class-switched, antigen-specific antibody production. Blood 129(8): 959-969, 2017. PMID: 28077418. DOI: 10.1182/blood-2016-04-709584

91 Takahashi T, Katano I, Ito R, Goto M, Abe H, Mizuno S, Kawai $\mathrm{K}$, Sugiyama $\mathrm{F}$ and Ito $\mathrm{M}$ : Enhanced antibody responses in a novel NOG transgenic mouse with restored lymph node organogenesis. Front Immunol 8: 2017, 2018. DOI: 10.3389/fimmu.2017.02017

92 Zeng Y, Liu B, Rubio M-T, Wang X, Ojcius DM, Tang R, Durrbach A, Ru Z, Zhou Y and Lone Y-C: Creation of an immunodeficient HLA-transgenic mouse (HUMAMICE) and functional validation of human immunity after transfer of HLAmatched human cells. PloS One 12(4): e0173754-e0173754, 2017. PMID: 28399128. DOI: 10.1371/journal.pone.0173754

93 Izumchenko E, Paz K, Ciznadija D, Sloma I, Katz A, VasquezDunddel D, Ben-Zvi I, Stebbing J, McGuire W, Harris W, Maki R, Gaya A, Bedi A, Zacharoulis S, Ravi R, Wexler LH, Hoque MO, Rodriguez-Galindo C, Pass H, Peled N, Davies A, Morris R, Hidalgo $M$ and Sidransky D: Patient-derived xenografts effectively capture responses to oncology therapy in a heterogeneous cohort of patients with solid tumors. Ann Oncol 
28(10): 2595-2605, 2017. PMID: 28945830. DOI: 10.1093/ annonc/mdx 416

94 Zhan M, Yang R, Wang H, He M, Chen W, Xu S, Yang L, Liu Q, Long M and Wang J: Guided chemotherapy based on patientderived mini-xenograft models improves survival of gallbladder carcinoma patients. Cancer Commun 38(1): 48, 2018. DOI: 10.1186/s40880-018-0318-8

95 Scott CL, Mackay HJ and Haluska P, Jr.: Patient-derived xenograft models in gynecologic malignancies. Am Soc Clin Oncol Educ Book: e258-e266, 2014. PMID: 24857111. DOI: 10.14694/EdBook_AM.2014.34.e258

96 Hidalgo M, Amant F, Biankin AV, Budinská E, Byrne AT, Caldas C, Clarke RB, de Jong S, Jonkers J, Mælandsmo GM, RomanRoman S, Seoane J, Trusolino L and Villanueva A: Patientderived xenograft models: An emerging platform for translational cancer research. Cancer Discov 4(9): 998-1013, 2014. PMID: 25185190. DOI: 10.1158/2159-8290.CD-14-0001

97 Junttila MR and de Sauvage FJ: Influence of tumour microenvironment heterogeneity on therapeutic response. Nature 501(7467): 346-354, 2013. DOI: 10.1038/nature 12626
98 Reconstitution of a human immune system in a patient derived xenograft (PDX) model of genitourinary (GU) cancers (immune PDX). ClinicalTrials.gov Identifier: NCT03134027. Available at: https://clinicaltrials.gov/ct2/show/NCT03134027

99 Sanmamed MF, Rodriguez I, Schalper KA, Oñate C, Azpilikueta A, Rodriguez-Ruiz ME, Morales-Kastresana A, Labiano S, Pérez-Gracia JL, Martín-Algarra S, Alfaro C, Mazzolini G, Sarno F, Hidalgo M, Korman AJ, Jure-Kunkel M and Melero I: Nivolumab and urelumab enhance antitumor activity of human T lymphocytes engrafted in Rag2--IL2R $\gamma$ null immunodeficient mice. Cancer Res 75(17): 3466-3478, 2015. PMID: 26113085. DOI: 10.1158/0008-5472.Can-14-3510

Received July 28, 2020

Revised August 14, 2020

Accepted August 25, 2020 